\title{
Sexual Abuse of Children through Internet. May a Dissociative Disorder Explain the Fact? A Case Report
}

John E Berg*

Professor Emeritus, Specialist in Psychiatry and Occupational Medicine, Oslo Metropolitan University, Norway

*Corresponding author: Berg JE, MD PhD, Professor Emeritus, Specialist in Psychiatry and Occupational Medicine, Oslo Metropolitan University, Pilestredet 48. 0130 Oslo, Norway, Tel: 0047-92090438; E-mail: john@pong.no

Received: June 20, 2021; Accepted: June 26, 2021; Published: June 30, 2021

\begin{abstract}
Post-traumatic stress after abuse early in life, leading to dissociative actions may be forgotten until late in life. An example of this is demonstrated in a case report from a resident psychiatric facility in Northern Norway. Under Norwegian Law, acts under dissociation does not qualify as not fit for standing trial, but may be deemed a partial excuse. In the present case a sentence of 5 months was the result of court proceedings where dissociation was duly taken into account.
\end{abstract}

Keywords: Childhood trauma; Dissociation; Sexual abuse through internet

\section{Case Report}

A 68-year-old man without any former contact with psychiatric care was referred to an outpatient resident facility because of isolation, anxiety and personal neglect. Two years before his referral he was summoned to the local police because of connections to a national pedophilic ring on the internet. Until that time he had led an inconspicuous life with a family, a daughter and a job. After police interrogation he had a cerebral insult in the cell and was transferred to hospital for emergency treatment. He woke up partially incapacitated and could not speak. Several memories from childhood later emerged. He was physically abused by his father and he revealed these memories to his daughter. During resident treatment he vehemently rejected being sexually abused at home, but reluctantly confirmed what he had told his daughter. He maintained that from his childhood until after his cerebral insult, he had not thought about the abuse.

A forensic investigation by a psychiatrist and a psychologist was ordered by the court. The forensic experts followed the court trials. The experts maintained that he had no posttraumatic stress disorder, which is correct since he did not have a lifethreatening experience earlier in life. He reported no flashbacks or nightmares and more generally was unaware of childhood

Citation: Berg JE. Sexual Abuse of Children through Internet. May a Dissociative Disorder Explain the Fact? A Case Report. Clin Case Rep Open Access. 2021;4(2):188. 
www.yumedtext.com | June-2021 | ISSN: 2582-5038 | https://dx.doi.org/10.46527/2582-5038.188

violence. During his stay at the outpatient resident facility, he told the author about a good me and a bad me, and that it must have been the bad me who was responsible for internet related sexual activity. The author interpreted this as possible dissociation. Complex posttraumatic stress disorder may be an alternative explanation. Then you often have no or faint memory of the violent acts you lived with and could not escape from, but you may experience some of the material through dissociation.

\section{Discussion}

Whether dissociation may partly or at all explain sexual activities with children over the internet has not been studied. The author found no such studies in Pub Med searches. The court, as described above, did not find clear evidence that such connection might exist, but could neither dismiss it. The court experts probably did not differ between posttraumatic stress disorder proper with prior death threats and complex posttraumatic stress disorder with non-escapable violence and stress.

The present case illustrates findings of Akyüz et al from [1]. They randomly selected 101 male prisoners and interviewed them with relevant scales for dissociation and PTSD. The probands reported high frequencies of criterion. A trauma (85.2\%) and lifetime PTSD (66.4\%). Dissociative experiences were also more frequent than in the general population. Childhood trauma occurred at high rates among the prisoners.

Bourget et al found that claims of amnesia and dissociative experiences in association with a violent crime are not uncommon [2]. These may have relevance to the legal constructs of fitness to stand trial, criminal responsibility, and diminished capacity. From the standpoint of forensic psychiatry cases of offenders pretending dissociation during violent acts to explain behaviour would be frequent. Usually, the experts do not investigate the possibility of the presence of complex posttraumatic stress disorder as the basis for later dissociation. Whether the acts in the present case are compatible with what may be done under dissociation is unsettled from scientific studies. More studies are needed.

\section{REFERENCES}

1. Akyüz G, Kugu N, Sar V, et al. Trauma and dissociation among prisoners. Nord J Psychiatry. 2007;61(3):167-72

2. Bourget D, Gagné P, Wood SF. Dissociation: Defining the concept in criminal forensic psychiatry. J Am Acad Psychiatry Law 2017;45(2):147-60. 